\title{
The Impact of Competitive Strategy on Profitability in the Context of COVID-19: A Case Study of McDonald's
}

\author{
Han $\mathrm{Ma}^{1}$ \\ ${ }^{1}$ School of Business Administration, Zhuhai College of Jilin University, Zhuhai, China
}

\begin{abstract}
In the context of the outbreak of COVID-19, public life and corporate profits have been influenced greatly. This paper takes McDonald's as the case study object to explore the impact of competitive strategy on corporate profitability. Through investigation, it is found that McDonald's profitability and operation are generally good due to its accurate competitive strategic positioning. However, under the impact of COVID19, the profit is slightly weak. Therefore, the paper helps clarify the concept that a reasonable competitive strategy has a positive effect on the profitability of enterprises. At the same time, this paper puts forward some views on the implementation of the strategy for the enterprises that take McDonald's as the typical one to implement the cost leadership strategy. Besides, this paper also makes an appropriate extension on how enterprises should respond to such crisis situations as COVID-19 at the level of competitive strategy, which provides a new way for enterprises to get through the crisis.
\end{abstract}

\section{Introduction}

In late 2019, an unprecedented public health event erupted. COVID-19 quickly swept the world, while bringing great harm to the lives of the people, also had a significant impact on the enterprises. According to incomplete statistics, more than 4 million people have been diagnosed globally, more than 80 percent of the global workforce has been affected, and a large number of small, medium and micro-sized enterprises have closed. Meanwhile, large chain companies such as McDonald's, Starbucks and Apple have also experienced mass shutdowns. Among them, McDonald's suspended all company-operated restaurant service in America on March 16th, and on March 23rd, it closed all its restaurants in Ireland and the U.K. COVID19 is a tough challenge for all enterprises. To overcome one of the major difficulties, a reasonable corporate competitive strategy is particularly important.

Based on the above background, this paper will focus on the exploration of competitive strategy, and competitive strategy after years of development has had a relatively complete theoretical basis. The competitive strategy includes cost leadership strategy, differentiation strategy and focus strategy $[1,2]$. Porter believes that enterprises must choose one of the three strategies as their dominant strategy to achieve the leading position in the industry. Consistent with porter's original concept, some take an anatomical perspective and consider cost leadership, differentiation, and focus as three different types of strategies [3]. Others maintain the sharp contrast view that strategies should be integrated to form combinative strategies, which is more conducive to enterprises to adapt to the turbulent business environment $[4,5]$. So, how to understand the three strategies of cost leadership, differentiation and focus? Cost leadership is a strategy for enterprises to reduce costs through effective ways and make their total cost lower than the cost of competitors, or even the lowest cost in the same industry, so as to gain competitive advantages. Cost control is at the heart of a cost-leadership strategy, which allows a firm to fetch above-average returns [6]. In general, we expect chain restaurants like McDonald's, which are highly competitive and not differentiated, to adopt a cost leadership strategy [7]. Differentiation strategy refers to a strategy adopted to make the products of an enterprise distinct from those of competitors and to form distinctive characteristics. The core of this strategy is to achieve something unique that is valuable to the customer, and a prime example of this strategy is Apple. Finally, the focus strategy, which refers to a strategy in which the business activities of an enterprise or business division are concentrated on a specific buyer group, a part of the product line or a certain geographical market. In recent years, some research on competitive strategy in academia often focuses on entrepreneurship orientation and the choice of policy in the early stage of entrepreneurship or are often linked to firm performance [8-12], and case studies looking at micro, small and medium-sized companies or family businesses [13-16].

The above literature is the academic research and discussion on competitive strategy over the years, which has made outstanding contributions to the field of competitive strategic positioning. However, the study on the implementation of strategic positioning and profit effect of large chain enterprises is relatively weak. It is well known that the fundamental purpose of an enterprise is to make profits, which is a major measure of how well an 
enterprise operates. Therefore, this study will take McDonald's as an example to explore the impact of the enterprise's current competitive strategy on profitability. At the same time, the sudden outbreak of the COVID-19 world pandemic in 2020 has brought great harm to all enterprises. Under such a background, whether the reasonable strategic positioning of enterprises can guarantee less profit loss is also the focus of this thesis.

\section{Method}

In order to intuitively show the implementation effect and profitability of McDonald's strategy, we collected data on the balance sheet items (inventory, accounts payable, accounts receivable, etc.) and income statement items (revenue and cost of goods sold, etc.) of McDonald's in the

past five years, which are from the McDonald's annual reports on the website of the U.S. SECURITIES AND EXCHANGE COMMISSION. Then, we built the formula model with EXCEL and imported the data with unified accuracy into the model to analyze the profitability, liquidity and ROCE of McDonald's. For the operation of McDonald's under the influence of COVID-19, the analysis data are still from the first quarter of 2020 report released by McDonald's on the website of the U.S. SEC. We extracted some data related to profit for analysis and discussion.

\section{Results and Discussion}

\subsection{Cost of goods sold}

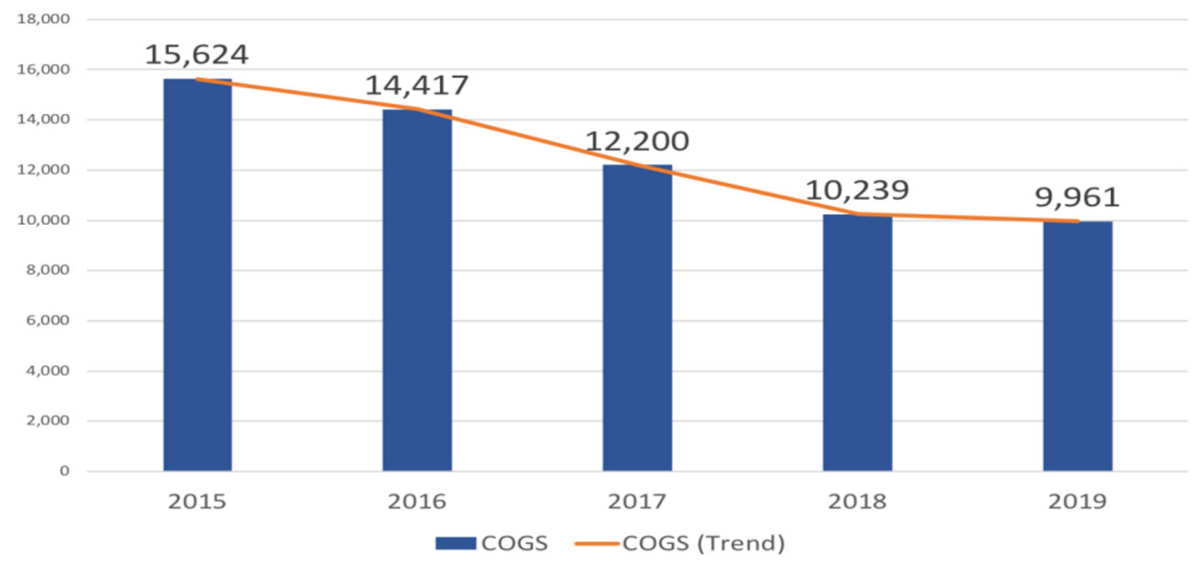

Fig1. McDonald's recent cost trends. [17-21]

Among porter's three competitive strategies, McDonald's has always pursued a cost leadership strategy and excelled in cost control. As can be clearly seen from the figure above, McDonald's cost of goods sold (COGS) has been on a downward trend in recent years, with a significant decline between 2015 and 2018. In these three years, the year-on-year decrease rate of its COGS was $8.37 \%, 18.17 \%$ and $19.15 \%$, respectively. Despite a slowdown in the fall in cost of goods sold from 2018 to 2019, it is still on a downward trend and has managed to fall below $\$ 10,000$ million.

As mentioned above, the fundamental goal of the cost leadership strategy is to reduce the cost as much as possible on the premise of ensuring product quality, so as to occupy the dominant position in the industry. From the above data analysis, McDonald's is quite strict in the control of costs, and its implementation of cost leadership strategy is outstanding.

According to the data analysis, the cost of goods sold by McDonald's has been decreasing year by year. The reasons for this achievement mainly include the following

measures. Firstly, McDonald's has always been willing to keep looking for cheaper real estate as restaurants sites. Also, equipment and decoration materials are unified procurement, so as to reduce the cost. Secondly, a unique model called Hourly Labor Guide (HLG) is used by McDonald's to determine the number of employees to hire. HLG refers to the approximate proportion of turnover and working hours found after long-term observation, which can help McDonald's optimize the employee system and maximize efficiency. This model saved McDonald's a lot of labor costs. In addition, as for the cost of raw materials, McDonald's has an excellent and stable trading relationship with suppliers, and McDonald's orders are huge, which are the reasons why McDonald's can buy raw materials at a low price. Finally, to save energy, McDonald's has created a unique energy monitoring system called Dotsystem, clearly grasp the use time of each machine and energy, avoid unnecessary waste.

\subsection{Profitability \& Liquidity}

Table1. McDonald's turnover in the last five years. [17-21]

\begin{tabular}{|c|c|c|c|c|c|}
\hline Year & 2015 & 2016 & 2017 & 2018 & 2019 \\
\hline Accounts Receivable Turnover & 20.2 & 17.8 & 13.2 & 9.5 & 9.0 \\
\hline Days Receivables Held & 18 & 21 & 28 & 38 & 40 \\
\hline Inventory Turnover & 148.7 & 181.3 & 207.3 & 186.3 & 196.7 \\
\hline Days Inventory Held & 2 & 2 & 2 & 2 & 2 \\
\hline Accounts Payable Turnover & 18.0 & 17.6 & 14.5 & 9.6 & 9.1 \\
\hline Days Payables Held & 20 & 21 & 25 & 38 & 40 \\
\hline Net Working Capital Days & 0 & 2 & 4 & 2 & 2 \\
\hline Revenues / Average Net Fixed Assets & 1.07 & 1.11 & 1.04 & 0.93 & 0.90 \\
\hline
\end{tabular}




\begin{tabular}{cccccc} 
Cash Turnover & 5.2 & 5.5 & 12.4 & 12.6 & 23.9 \\
Days Sales Held in Cash & 70.1 & 66.0 & 29.5 & 28.9 & 15.3 \\
\hline
\end{tabular}

Statistically, the company's accounts receivables turnover from 2015 to 2019 continued to decline (from 20.2 to 9.0), which meant that McDonald's receivables collection was slower and slower, and its stagnant operating capital on receivables gradually increased. But at the same time, McDonald's accounts payable turnover has been declining year by year. The extension of accounts payable payment days retained sufficient working capital for the enterprise to offset the negative impact of accounts receivable payment days long. Besides, the inventory turnover rate has always been maintained at a relatively stable level, inventory turnover days have been 2 days. This indicates that McDonald's is in excellent condition of incoming and shipment, and the operation of the restaurant is stable, avoiding unnecessary waste of storage costs. Above ratio, it can be seen that under the cost leadership strategy, McDonald's operation efficiency is higher, and it has certain advantages in the industry.

Table2. McDonald's ROCE in the last five years. [17-21]

\begin{tabular}{|c|c|c|c|c|c|}
\hline Year & 2015 & 2016 & 2017 & 2018 & 2019 \\
\hline Profit Margin for ROCE & $17.8 \%$ & $19.0 \%$ & $22.8 \%$ & $28.2 \%$ & $28.6 \%$ \\
\hline $\mathrm{x}$ Asset Turnover & 0.7 & 0.7 & 0.7 & 0.6 & 0.5 \\
\hline x Capital Structure Leverage & 3.6 & 14.1 & -11.8 & -7.0 & -5.6 \\
\hline$=$ Return on Common Equity & $45.4 \%$ & $191.9 \%$ & $-189.8 \%$ & $-124.4 \%$ & $-83.3 \%$ \\
\hline
\end{tabular}

Return on common equity is a measure of how well a company uses its investment dollars to generate profits. From the data of 2015 and 2016, McDonald's operation results are relatively ideal. But since 2017, McDonald's has had a negative ROCE. According to financial news, this was caused by McDonald's heavy share buybacks and excessive shareholder dividends. Nevertheless, we can still see that McDonald's ROCE was on the rise in the following years, which indicates that McDonald's is still doing well. The reason for the negative ROCE is not because of the deteriorating restaurant operation.

Table3. McDonald's liquidity in the last five years. [17-21]

\begin{tabular}{|c|c|c|c|c|c|}
\hline Year & 2015 & 2016 & 2017 & 2018 & 2019 \\
\hline Current Ratio & 3.27 & 1.40 & 1.84 & 1.36 & 0.98 \\
\hline Quick Ratio & 3.05 & 0.78 & 1.54 & 1.11 & 0.86 \\
\hline Operating Cash Flow to Current Liabilities & $229.5 \%$ & $188.8 \%$ & $174.6 \%$ & $237.6 \%$ & $246.3 \%$ \\
\hline
\end{tabular}

McDonald's current ratio generally shows a downward trend. Since 2016, the current ratio has fallen below 2:1. It seems to mean that McDonald's short-term solvency is poor and will make it harder for companies to raise capital, which will affect profitability. But in terms of the quick ratio, the results are quite different. Since 2016, McDonald's quick ratio has fluctuated around 1, which is a relatively appropriate ratio for a company. The quick ratio eliminates the effect of inventory on the current ratio and reflects the ability of the enterprise to repay its debts immediately. Relatively speaking, the quick ratio reflects the solvency of enterprises more accurately, and the quick ratio of enterprises keeps at a more appropriate value, which also indicates the strong profitability of enterprises.

Through the analysis of McDonald's turnover rate, ROCE and liquidity in the past five years, we can get a noticeable result. Under normal circumstances, McDonald's is in good operating condition, with strong profitability and stable cash flow, which makes it the world's largest fast-food chain.

\subsection{The operations under the influence of COVID-} 19

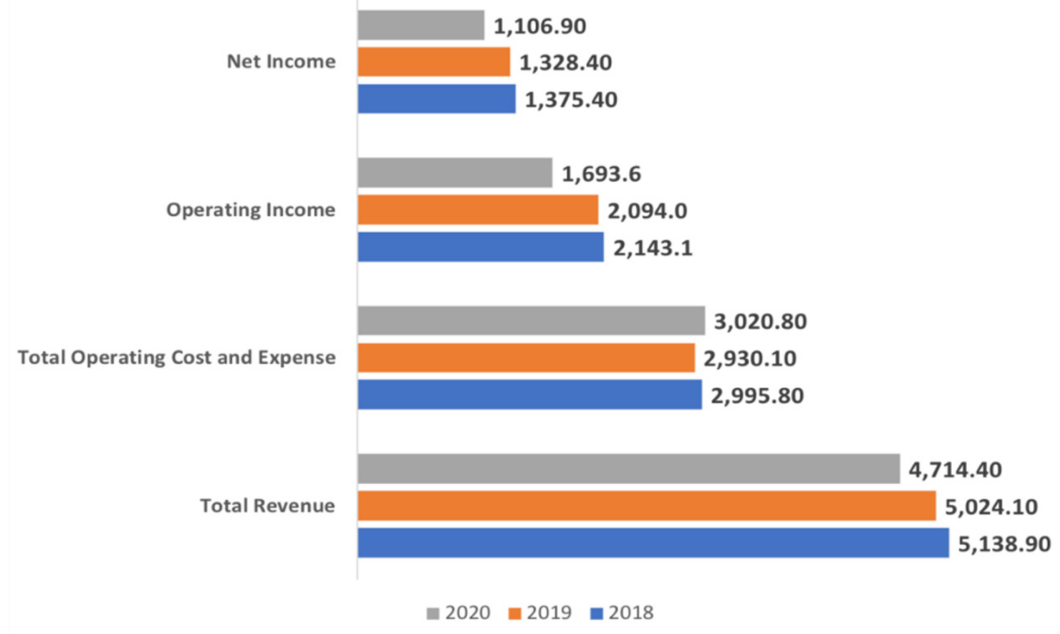

Fig2. McDonald's operations in the first quarter of the last three years. [17-21] 
To visualize the impact of COVID-19 on McDonald's earnings, we selected McDonald's operating profit in the first quarter of the last three years for vertical comparison. As can be clearly seen from the figure above, under the influence of COVID-19, McDonald's profit in the first quarter of 2020 showed a significant decline. Compared with the same period in 2019 , its revenue declined by $6.16 \%$, its operating income by $19.12 \%$ and its net income by $16.67 \%$. In contrast, revenue, operating income and net income fluctuated slightly in 2018 and 2019, but were essentially flat, which is also reflect the damage caused by COVID-19 to McDonald's operation. Besides, as for costs and expenses, McDonald's failed to reduce them with the decrease in revenue. The operating costs of McDonald's in the first quarter of 2020 were the same as those in the other two years, or even rose slightly, which undoubtedly hit McDonald's a lot.

In the face of the sudden outbreak of COVID-19, there are crises of varying degrees in enterprises of all sizes around the world, and McDonald's has certainly not been spared. As the data analysis can be seen, McDonald's suffered a significant decline in revenue and profit in the face of the impact of COVID-19. According to McDonald's first-quarter 2020 report, the main reasons for its revenue decline include the ongoing temporary restaurant closures, limited operations and dramatic changes in consumer behavior, all of which were caused by COVID-19. At the same time, McDonald's believes the outbreak will continue to have a significant negative impact on revenue.

Besides, it is worth noting the changes in McDonald's operating costs under the influence of COVID-19. As an enterprise that pursues cost leadership strategy, McDonald's failed to stick to its strategic positioning under the crisis. When a large number of stores were closed, operating costs increased slightly over the same period last year, which should not have happened. The reason for this may be that the outbreak of COVID-19 has broken McDonald's original relatively stable cost structure, and it failed to make corresponding adjustments in time. For example, according to McDonald's quarterly report, in order to better generate revenue during the outbreak, McDonald's actively provides delivery services. This means that the number of deliverymen needs to be increased, and the labor cost has not been reasonably optimized through the McDonald's HLG model so that the labor cost may increase. Since the labor cost increased due to special circumstances, the cost of raw materials, energy and other costs also increased due to insufficient adjustment, which led to the increase of the total cost instead of falling.

\section{Conclusion}

Through the analysis of the above cases, the following outcomes and extensions can be obtained. Firstly, as far as McDonald's is concerned, its profitability is generally better under normal conditions, which is related to the accurate positioning of its competitive strategy and effective implementation measures. However, in the face of COVID-19, McDonald's profit was weak. In addition to the decline in revenue, McDonald's failed to adequately control its costs was more important, which led to the overall decline in profit and greatly affected its profitability. Therefore, it is clear to be seen that an enterprise's competitive strategy to its profit image, only to have an effective and reasonable competitive strategy and constantly put into practice measures, to ensure the enterprise's competitive advantage in the industry.

Secondly, cost leadership strategy is a pre-emptive strategy, to achieve the strategic objectives that require the enterprise to have a sustained capital investment and financing capacity, production skills in the industry in a leading position. As the practitioner of cost leadership strategy, McDonald's provides a good example for this theory. Its capital turnover rate is good, and it has sufficient capital to implement cost leadership. In addition, the focus of the cost leadership strategy should be to optimize the cost structure and reduce the cost, rather than blindly reduce the product price. Enterprises with the same strategy will inevitably lead to a price war. If the enterprise takes the lead in reducing the price to a minimum value, and the current cost is not enough to support the continued reduction of the price, it will lead to malicious bidding by competitors and put the enterprise at a competitive disadvantage. At the same time, in order to optimize the cost structure, enterprises should also have their own unique management methods that are not easily imitated by competitors, such as McDonald's HLG model and Dotsystem.

Thirdly, the outbreak of COVID-19 is unexpected, and it has brought an inevitable huge blow to many enterprises. This prompts us to think about how enterprises should respond to such sudden crisis events and what measures should be taken at the level of strategy. In order to be able to cope with all kinds of sudden crisis, the enterprise's competitive strategy should be increasingly diversified. Just think, if the strategic positioning of a certain enterprise is relatively single, and the sudden crisis incident hits the profit core of the enterprise, then it is difficult for the enterprise to have sufficient funds and flexible measures to compete with it. The end result is likely to be that the enterprise can no longer support the experience and is unable to transform, leading to bankruptcy. A case in point is the number of companies facing bankruptcy in this COVID-19 crisis. For diversified enterprises, their response to the crisis will be relatively more leisurely. First, diversified development helps enterprises avoid risks. Take the COVID-19 outbreak, the traditional restaurant industry has been hit hard while supermarket chains have seen their profits soar. This illustrates that the same kind of crisis cannot be targeted at all types of enterprises, so the reasonable diversification of the industry is to diversify the risk. Second, diversified enterprises are more flexible in operation, and they can adjust their business focus to maximize profits in response to different crisis situations. To sum up, after experiencing a huge crisis in the whole society, enterprises should think about the development direction of strategy in the future. It is not necessarily a bad thing to try to develop in the 
direction of diversification under the conditions of capital and other conditions.

This paper only focuses on the case study of McDonald's, which is representative of many restaurant chains and enterprises pursuing a cost leadership strategy. Due to the limitation of the types of enterprises, this paper has not carried out an in-depth discussion on the enterprises that pursue other competitive strategies. However, in the future academic research, scholar will select different types of enterprises to conduct data analysis and explore the general rules and conclusions behind the data.

\section{References}

1. Porter $\mathrm{M}$ E. Competitive advantage of nations: creating and sustaining superior performance[M]. simon and schuster, 2011.

2. Porter M E. Competitive strategy: Techniques for analyzing industries and competitors[M]. Simon and Schuster, 2008.

3. Dess G G, Davis P S. Porter's (1980) generic strategies as determinants of strategic group membership and organizational performance[J]. Academy of Management journal, 1984, 27(3): 467488.

4. Beal R M, Yasai-Ardekani M. Performance implications of aligning CEO functional experiences with competitive strategies[J]. Journal of Management, 2000, 26(4): 733-762.

5. Subramanian R, Gopalakrishna P. The market orientation-performance relationship in the context of a developing economy: An empirical analysis[J]. Journal of Business Research, 2001, 53(1): 1-13.

6. Miller D, Friesen P H. Porter's (1980) generic strategies and performance: an empirical examination with American data: part I: testing Porter[J]. Organization studies, 1986, 7(1): 37-55.

7. Cotterill R W. Competitive strategy analysis in the food system[M]. CRC Press, 2019.

8. Block J H, Kohn K, Miller D, et al. Necessity entrepreneurship and competitive strategy[J]. Small Business Economics, 2015, 44(1): 37-54.

9. Hernández-Perlines F, Moreno-García J, YañezAraque B. The mediating role of competitive strategy in international entrepreneurial orientation[J]. Journal of Business Research, 2016, 69(11): 5383-5389.

10. Bayraktar C A, Hancerliogullari G, Cetinguc B, et al. Competitive strategies, innovation, and firm performance: an empirical study in a developing economy environment[J]. Technology Analysis \& Strategic Management, 2017, 29(1): 38-52.

11. Santos-Vijande M L, López-Sánchez J Á, Trespalacios J A. How organizational learning affects a firm's flexibility, competitive strategy, and performance[J]. Journal of Business Research, 2012, 65(8): 1079-1089.

12. Hsieh Y H, Chen H M. Strategic fit among Business
Competitive Strategy, Human Resource Strategy, and Reward System[J]. Academy of Strategic Management Journal, 2011, 10(2).

13. Panwar R, Nybakk E, Hansen E, et al. The effect of small firms' competitive strategies on their community and environmental engagement[J]. Journal of Cleaner Production, 2016, 129: 578-585.

14. Agyapong A, Ellis F, Domeher D. Competitive strategy and performance of family businesses: moderating effect of managerial and innovative capabilities[J]. Journal of Small Business \& Entrepreneurship, 2016, 28(6): 449-477.

15. Acquaah M, Agyapong A. The relationship between competitive strategy and firm performance in micro and small businesses in Ghana: The moderating role of managerial and marketing capabilities[J]. Africa Journal of Management, 2015, 1(2): 172-193.

16. Acquaah M, Amoako-Gyampah K, Jayaram J. Resilience in family and nonfamily firms: an examination of the relationships between manufacturing strategy, competitive strategy and firm performance $[\mathrm{J}]$. International journal of production research, 2011, 49(18): 5527-5544.

17. 2015 annual report on U.S. SECURITIES AND EXCHANGE COMMISION, [online] Available: https://www.sec.gov/cgi-

$\mathrm{bin} /$ viewer?action=view\&cik $=63908$ \&accession nu mber $=0000063908-16-000103 \& x b r l$ type $=\mathrm{V}$

18. 2016 annual report on U.S. SECURITIES AND EXCHANGE COMMISION, [online] Available: https://www.sec.gov/cgi-

bin/viewer?action=view\&cik $=63908 \&$ accession_nu mber $=0000063908-17-000017 \& x b r l$ type $=\mathrm{V}$

19. 2017 annual report on U.S. SECURITIES AND EXCHANGE COMMISION, [online] Available: https://www.sec.gov/ix?doc=/Archives/edgar/data/63 908/000006390818000010/mcd-12312017x10k.htm

20. 2018 annual report on U.S. SECURITIES AND EXCHANGE COMMISION, [online] Available: https://www.sec.gov/ix?doc=/Archives/edgar/data/63 908/000006390819000010/mcd-12312018x10k.htm

21. 2019 annual report on U.S. SECURITIES AND EXCHANGE COMMISION, [online] Available: https://www.sec.gov/ix?doc=/Archives/edgar/data/63 908/000006390820000022/mcd-12312019x10k.htm

22. 2020 first quarter report on U.S. SECURITIES AND EXCHANGE COMMISION, [online] Available:

https://www.sec.gov/ix?doc=/Archives/edgar/data/63 908/000006390820000042/mcd-3312020x10q.htm 